\title{
Research design for studying development in border areas: case studies towards the big picture?
}

Méthodologie de recherche sur le développement des zones frontalières: les études de cas peuvent-elles déboucher sur une vision globale?

\section{Sarolta Németh, Ágnes Németh and Virpi Kaisto}

\section{(2) OpenEdition}

\section{Journals}

Electronic version

URL: http://journals.openedition.org/belgeo/10582

DOI: $10.4000 /$ belgeo.10582

ISSN: 2294-9135

Publisher:

National Committee of Geography of Belgium, Société Royale Belge de Géographie

Electronic reference

Sarolta Németh, Ágnes Németh and Virpi Kaisto, « Research design for studying development in border areas: case studies towards the big picture? », Belgeo [Online], 1 | 2013, Online since 31 October 2013, connection on 19 April 2019. URL : http://journals.openedition.org/belgeo/10582 ; DOI : 10.4000/belgeo.10582

This text was automatically generated on 19 April 2019.

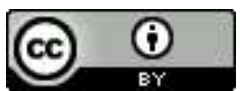

Belgeo est mis à disposition selon les termes de la licence Creative Commons Attribution 4.0 International. 


\title{
Research design for studying development in border areas: case studies towards the big picture?
}

\author{
Méthodologie de recherche sur le développement des zones frontalières: les \\ études de cas peuvent-elles déboucher sur une vision globale?
}

\author{
Sarolta Németh, Ágnes Németh and Virpi Kaisto
}

\section{Introduction}

The field of border studies has flourished during the last three decades. Especially since the beginning of the new millennium, a vast amount of scholarly work has been produced in a multitude of disciplines ranging from political science, economy and geography to sociology, ethnology and psychology. The great diversity of approaches to the concept of "border" has shed a light on the spatial and temporal embeddedness and heterogeneity of borders. It has also led to the proliferation of in-depth, descriptive-analytical case studies from different European and other border areas. Border scholars have been concerned about the consequent fragmentation of evidence. They have been calling for comparative approaches, and common concepts and models for studying border regions (Newman, 2003; Liikanen, 2010) and welcome the emerging "postdisciplinarity, a convergence in approaches, theories, conceptualizations and methodologies" (Wilson \& Donnan, 2012). Despite the evident consensus among border scholars that a single "grand border theory" is not achievable (Paasi, 2009; Newman, 2006), this type of convergence and crossfertilisation of border researches in various (multi-) disciplines is a way to deepen our understanding of the past, current and future dynamics of borders.

2 In this paper we ask how it is possible to proceed, after establishing the fact that borders and border related phenomena are unique place-specific constellations, towards the somuch-desired convergence in conceptualisations and analytical tools in border studies? 
How can multiple-case studies reach valid generalisations? We analyse four recent international, European-scale research projects that study the development in several different border areas and see how they have applied a multiple-case study approach to produce both on the one hand, regional- or case-specific research results, and on the other hand, messages that bear relevance to general border theories and higher, European level policy making. Two of these researches, Ulysses and Terco were both carried out during 2010-2012 in the ESPON 2013 programme. These projects were concerned with territorial development and co-operation at EU internal and external borders. The project titled Euborderregions, implemented in 2011-2015 under the EU's ongoing Seventh Framework Programme for Research and Technological Development (FP7), has cross-border co-operation and interaction in its focus and it deals exclusively with the EU's external border and the Neighbourhood. Finally, the Unfamiliarity (funded by ESF - the European Science Foundation - and several national academic funds) initiative serves as an umbrella for a set of multidisciplinary collaborative research projects that share the aim of investigating the "softer" constituent elements of bordering such as dialect and language, religion, historical geography, ethnogenesis, invented tradition and material culture, but otherwise handle very different cases.

3 Three of the research projects that we use as examples in our study represent the regional policy/development strand of border studies (see Kolossov, 2005), which investigates the relationship between regional/territorial development and interactions across the border. In Europe this particular aspect of analysing borders has become popular for two interrelated reasons. Firstly, national borders became differentiated with the Schengen Agreement in 1985 and new centre-periphery relationships and integration and co-operation zones emerged. A few years later in 1993 the European Union emerged as a new (f)actor constructing and defining borders within its space and beyond. This led to an increased interest in the impact of borders on regional and territorial development. Border regions began to raise their profiles relating to their border proximity not only to capture European funding, but also to locally enhance cross-border co-operation and to overcome the disadvantages from their peripheral position. Secondly, EU itself became interested in monitoring the development of its border regions and the integration across the borders. This was connected with the realisation that EU policies have certain territorial impacts (the emergence of the European spatial planning discourse in the beginning of 1990s, see Böhme \& Gløersen, 2011; Eskelinen \& Fritsch, 2010). The EU began to direct considerable funding to large-scale, cross-European research projects that study the development in border areas - under its ESPON programme, and within subsequent Framework Programmes. The Unfamiliarity project, unlike the other three, has a much softer approach towards borders, and represents the strand in border studies which focuses on what Kolossov (2005) calls "borders as social constructs" and "social representations". The soft (de-)bordering processes are as important and organic elements in the development of borders and borderlands as their "harder", institutional counterparts. Therefore, researches like those within Unfamiliarity provide a good source of insight for border studies with a regional development perspective.

4 Since it is not possible to explore all the methodological details of these four research projects in the limits of a paper, the focus here is on two major aspects that have an impact on the research designs and are connected to the need for abstraction from specific contextual cases: the advantages and difficulties of a comparative framework and ways to achieve multi-level policy relevance of the research results. 


\section{Conceptualisation of diversity from multiple cases: shall we compare?}

5 Borders are more than lines marking the limits of a specific territory. They can be studied as obstacles in the way of different flows and interactions. Borders are often direct, physical barriers of passage with protective controls such as border checkpoints, visa regimes, taxes. Also, indirectly, in more subtle ways, they affect the behaviour of people. However, this may as well be turned around and then we see different practices of bordering (as well as "ordering" and "othering", van Houtum \& van Naerssen, 2002) and also a border emerging as a social construct: produced by unfamiliarity, prejudice, even distrust and fear (Valentine, 2008). Physical borders can be removed relatively easily as compared to mental borders, which latter in fact can be rather "sticky" (van Houtum, 1999). Borders are hence lines of simultaneous inclusion and exclusion, no matter how high "physical barrier" they pose, with perceptions and representations attached to them (e.g. Scott, 2006).

6 Furthermore, a border, marking some positive distinction or an appealing degree of unfamiliarity (rational or perceived/emotional), can be regarded as an important asset for regional development: tourist attraction (e.g. Timothy, 1995), an interface of functional complementarities and source of synergies, a site of resource-sharing, crosscultural learning or lines with gateways of strategic significance. In this approach, borders or at least, certain sections of them, are stimulating and eventful sites of interaction, co-operation $(\mathrm{CBC})$ and integration, giving rise to novel governance structures (e.g. Euregions and EGTCs in Zapletal, 2010) and even, distinct (cross-border) regional identities (van Houtum \& Lagendijk, 2001).

7 Certainly, there is great diversity of border types, and borders are as well, dynamically changing. Comparing different cases across time and/or space emerges as an inevitable need and opportunity for researchers to develop typology and fulfill the expectations for generalisation. Yet this requires caution, too. A multi-case border study may choose a systematic and explicit comparative framework that applies standardised data-collection tools and (mostly quantitative) analyses to a larger number of (randomly selected) cases that are representative of all, e.g. European, border-types, and then attempt at drawing "universal laws" or at least, "general rules" (i.e. the two most "extreme" aims of generalisation, see Mayring, 2007). Nonetheless, experience shows (also below) that this approach has several pitfalls and limitations at all of these different stages of the research process. A more implicit "comparison" can be carried out that allows for the implementation of qualitative analyses, of fewer and less intentionally selected cases in order to better understand certain processes and their significance in the development of borders and borderlands (i.e. an explorative study, or "interpretive research" where generalisation is rejected as the ultimate goal of research; ibid. and Denzin, 1983). What is important is to avoid confusing these two approaches in a research project while making abstractions on different levels and drawing general inference. 


\section{Policy-applicability of border case studies}

8 Research on borders and border area development had and continues to have important regional development policy implications. Most of such policy interest comes either from the European or the regional level. On the regional level, it is important to understand the European-wide development processes and position oneself as a region in comparisons with other borderlands (learning from differences, similarities, analogous processes etc.) and within the "big picture" (e.g. the European neighbourhood and policy). From the perspective of the EU, territorial integration in cross-border areas is regarded as an asset for increasing the EU's global competitiveness, and diminishing socio-economic and ecological fragmentation (EU Territorial Agenda 2011).

Obviously, research related to the development of borders and borderlands needs to take different political and policy interests into consideration at least as major factors influencing the developments along and across borders, even if research funding does not come straight from policy making bodies. Yet, in order to monitor (get "evidence" about) developments, the European Commission and the regions are relatively active in encouraging border research with financial support. It is interesting to note, that national states' perspectives are not so clear regarding this; ministries seem to be the last ones to be concerned. In any case, research projects funded by the EU, driven by the pressure by competition for resources, will try and serve the aims of policy making in more direct ways. This is of course, should not be by "adjusting" findings to fit certain political interests, but at any rate, this attempt manifests in the emphases on certain research questions, the choice of approaches, foci, methodologies as well as in ways of communicating and presenting findings. Even this last instance is a crucial aspect, that is, the delivery of research results in a policy-maker-friendly way. Altogether, these issues are most often referred to as parts of the requirement to produce applicable, implementable, "policy-relevant" yet still scientifically grounded messages or even, recommendations.

Meanwhile, there is a need to differentiate research findings according to what spatial scale they are most relevant at. This becomes an intricate issue when border research is funded by the European Union, and the project answers the call by promising and implementing a cross-European ("multi-border") study to produce "European" results. Research teams often face a dual pressure: they have to delve into "the great European diversity", i.e. the contextual, culturally, spatially etc. embedded processes that characterise different borders and then create punchy policy messages for the EU in the form of databases, general policy recommendations and thematic maps. The difficulty of this has been recognised by both parties, and highly descriptive and often quite extensive case studies are appended to scientific reports besides the executive summaries. Surely, certain phenomena can only be described, explained, traced, and not measured, counted and "correlated"; and studies with a "soft" approach on perceptions and representations have the benefit that they critically challenge the researcher's own preconceptions. Even acknowledging that there needs to be a shift from "evidence based" towards an "evidence informed" policy making (Davoudi, 2006), the question arises whether and how regional case studies can be structured, compared, synthesized in a way that they can enlighten the European-level policy debate. 
11 Finally, starting from the identification of research problems (questions) until the translation of findings into policy messages, policy makers at the most appropriate levels can be addressed by way of "stakeholder engagement" at different stages in the research design. Implementing different depth of stakeholder engagement at the regional, national and European levels can contribute to a more interactive relationship between research and policy, and can better ensure that research produces the most pertinent information for decisions.

\section{Research design solutions to serve both discipline and policy: comparative framework and stakeholder engagement}

In the following it is discussed what solutions the four research projects have come up with in their research design in order to ease the tensions between, on the one hand, the demand for abstractions and generalisations from in-depth, region-specific researches to enrich border theory and to serve policy makers at higher - European - levels and on the other hand, the need to advise local stakeholders and to present the complex ways how borders intertwine with social reality in specific "place-based" contexts.

\section{Ulysses}

13 Ulysses was a research project that studied the development of European cross-border areas (CBA), both across internal and external EU borders. Since it was realised in the ESPON 2013 program as "targeted analysis"1, its aim, on one hand, was to provide local stakeholders with information about territorial development in their own CBAs, and on the other hand, to inform policy makers on all (local, national and EU) levels about the more general territorial development trends related to CBAs in Europe.

The Ulysses project was realised as a multiple-case study and it included six case study areas. The selection of CBAs could not follow the replication logic (see Yin, 2009) because the "targeted analysis" research by definition had to be instigated by the needs of certain CBAs that wished to be part of such project. This however, resulted in a potentially biased selection: local stakeholders and research teams from different European CBAs were invited to take part in the project based on their initiative and interest in the theme of the study. Despite this "bottom-up" aspect of Ulysses, the project analysed a range of territorial issues and challenges that had been pin-pointed by European policies and previous ESPON research projects. Furthermore, the research design had to include a common methodology for all the case studies, with both quantitative and qualitative approaches to facilitate generalizations and the identification of wider European tendencies.

15 Firstly, an initial quantitative multi-thematic analysis, built on statistical data, was carried out to describe the regions' development courses and to compare those with the national and EU averages. The indicators, time frame and spatial scale (NUTS 2-3) were uniform across the case studies. Imposing such a common framework supported comparability of the research results - but also had its weaknesses. Comparable statistical data was hard to find for the regions outside the EU and the common frame left little room also for answering some specific questions raised by the local stakeholders. These 
latter had to be addressed separately on lower spatial levels, aiming at deeper understanding of the development trends. Nevertheless, this quantitative analysis could shed some light on wider European trends related to the development of CBAs by means of factor analyses. The European-level conclusions were based mainly on these statistical analyses in the first part of Ulysses because the comparison across entire, contextualized case studies proved to be an overwhelming task.

Secondly, Ulysses carried out cross-border governance analysis which addressed the comparability aspect by developing a special grouping of the CBAs. The CBAs were assessed along two dimensions drawing on different structural and dynamic conceptualizations of borders: 1) the function of the border as a "barrier", "interface" or "link", and 2) the intensity and continuity of cross-border co-operation, that is "neighbourhood", "co-operation" and "integration" areas. As mentioned in Ulysses Final Report (2012), the analysis can only show a synthetic and generalized picture of the CBAs, but it nevertheless helps to differentiate the various contexts, in which cross-border governance is tackled. In the third part of the Ulysses study, the findings from the multithematic analysis and the assessment of cross-border governance were fed into an integrated analysis in order to identify key problems and development challenges in the CBAs. For this purpose, a two-phase SWOT analysis was carried out, again as a standard, but this time, qualitative method applied across all CBAs.

In order to achieve high policy relevance (and fulfill the ESPON requirements of the "targeted analysis"), stakeholder participation was an essential part of Ulysses. The research was initiated by local stakeholders (with the support of Association of European Border Regions, AEBR), who by taking active part in the realisation of the project, ensured that findings of the study will be regionally relevant and applicable for writing cross-border development strategies. The research team had regular meetings with the stakeholders and AEBR (as the contact organisation of the stakeholders), and participated in the research / policy debates provided by the ESPON program in the form of ESPON Open Seminars and border area specific seminar sessions. The outcomes of the SWOT analysis were translated into strategies and policy options considering both the comparative European aspect and the case study specific findings. Finally, for the local stakeholders the research results and the visualisations (figures, tables and maps) not only contextualized their own CBAs in a wider European framework, but also stressed the importance of place-based strategies.

\section{Terco}

Terco, although having "international territorial co-operation" as the wider target of analysis (i.e. interpreting "border-crossing" from greater distances, not only within immediate borderlands), looked at how cross-border co-operation may contribute to the development of the regions involved, and what best practices exist to maximise its benefits. The Terco project, similarly to Ulysses, also carried out cross-European spatialstatistical analyses and implemented over a dozen descriptive "border region" case studies applying mainly qualitative tools (in-depth interviews, survey, etc.). The areas/ borders in this project, however, were selected in order to represent the existing diversity in Europe: borderlands in different geographical parts of Europe, along (old and new) EU-internal borders as well as EU-external borders; some of the borders examined stretching over land, some maritime; and some cases representing densely populated, 
more urbanised areas, while a few so-called "double peripheries". This was an expressed request by the ESPON programme's Coordination Unit and the external scientific experts in order to fulfil "representativeness" and facilitate regionally "balanced" European policy recommendations.

Another important feature of the research design was a "structural equation modelling" (SEM) exercise which was initially based on a thorough review of literature on territorial co-operation and border theory; it incorporated aspects of factors (obstacles and drivers), domains and governance of territorial co-operation and their assumed linkages to regional development. Then this model was also used as an analytical tool across the whole project. Partly in order to contribute to (and confirm) the SEM model, and also to be able to produce "European" policy messages (i.e. to advise CBC programmes), a standard empirical template was composed based on the hypotheses and the initial conceptual framework, in which researchers in each region had to address the same cross-cutting themes in their case study reports. This was however, facilitated already on the level of primary data collection via a standard questionnaire and expert interviews that had exactly the same thematic structure if not identical questions. During this routine, some contradictions and ambiguities emerged due to the diversity of the studied borders/regions; but in any case, this solution provided material for a (though very labour-intensive) cross-regional analytical-comparative synthesis, and consequently, for some general conclusions and EU policy recommendations.

As to the practical applicability of research outcomes, transfer of findings to policy makers could be realised on the regional and national, as well as the European level. In each Terco case study area the final regional reports were distributed to the stakeholders who were interviewed as experts. Besides, by way of being part of the ESPON programme monitored and funded by the European Commission and also by actively participating in ESPON forums and ECP (ESPON contact point) network, Terco could reach policy-making arenas at national and EU levels. It is interesting to mention that the analytical model developed in the project was also adapted for policy-advising purposes: the SEM model (relying also on empirical data from case studies), synthesized basically all factors related to the dynamics and functions of borders from the point of view of "how to make crossborder co-operation beneficial for regional development".

\section{Euborderregions}

In Euborderregions, the eleven case studies are located along different sections of the external border of the European Union and one of its main objectives is to advice the "neighbourhood policy (or policies)" of the European Union. It is among the initial hypothesis that although very different from internal-border situations, the external border of the EU is far from being homogenous also in terms of the real potentials for cross-border co-operation and (territorial) cohesion (see for interpretations in Böhme \& Gløersen, 2011). To investigate into this, mainly qualitative research methods are implemented (besides a few semi-quantitative attempts such as co-operation network analysis and an assessment of socio-economic development and disparities in the selected regions.) The reason given for this is that the shortage of comparative data from EUneighbourhoods practically limits the possibilities for statistical analyses; besides, the more intricate, policy-related and institutional processes of territorial cohesion, and the important geopolitical contexts cannot be described in terms of statistical figures. Thus 
the information sources and data collection methods include, among others, repeated and multi-faceted on-site observations, a minimum of fifty expert interviews with key stakeholders in each case, geopolitical and policy analyses and the review of experiences from other border studies carried out at the external borders. Nonetheless, similarly to the two ESPON projects, a standard case study template for findings ("table of contents") is used to describe all the studied cases (formed around the common research questions and shared typologies in the project) to facilitate ex-post comparisons and to distil messages from their individual findings that help to move towards a general model (i.e. applicable to further cases).

Finally, in terms of valorising findings in the regional, and also in the national context, the tool of stakeholder forums (an adjusted version of so-called "deliberative forums", Fishkin \& Laslett, 2003) with the participation of main regional actors is implemented towards the end of the extensive fieldwork period. The majority of participants come from those who have been interviewed as experts; and since due to the focus on external borders and the "neighbourhood" in this research, a few of them may even represent the national perspectives (ministries, etc.) These stakeholder forums address very specific problems related to the border in the studied regions, and contribute towards solving those problems with a focussed debate. The change in their perceptions of the given problem is measured by a short questionnaire after the discussion. Participants are also informed about the parallel researches at other external borders thus giving them the opportunity to position their "case" in wider, international processes. These events therefore serve not only data collection and verification, but also provide an interface between decision making and research on the regional-national level.

\section{Unfamiliarity}

The Unfamiliarity project is focused on the opinions and motivations of people both as influencing factors and as outcomes of cross-border interactions ( $C B C$, flows and international or bilateral relations). The social and cultural embeddedness of the border phenomena is the shared theoretical premise of all the included researches within the project, i.e. the conceptual framework built around perceptions and representations of (un)familiarity. This project has also a comparative case study design, but in a very special way. Not only the regions (and border relations) in foci are dissimilar but also the applied scientific disciplines and approaches, as well as the studied "media" or objects which bear the perceptions and representations of "unfamiliarity". To safeguard the comparative nature of this collaborative project, the individual sub-projects apply a shared border typology, and analyse different "old" inner border regions, "new" inner border regions and "new" outer borders across the European space; and therefore jointly they can produce information about these border types on a more general level. As a result, Unfamiliarity carries out comparisons in fact, at two levels in its research design: within its sub-projects (based on shared border typology); and then across their findings related to the different "daily practices" linked to the concept of "unfamiliarity" across borders. Besides, the frequent interdisciplinary discussions ensure cohesion within the project, contributing to the development of a common theoretical model.

Because of a relative dominance of humanistic approaches (ethnography, history) represented in Unfamiliarity, and because the research project is not directly aimed at regional development, there are no direct policy implications intended. However, it aims 
to learn how mental barriers for mobility are constructed and deconstructed in the minds of EU inhabitants, how historical commonalities and fractures have an impact on their representations of borders and 'otherness' and what influence political plans and media campaigns may have on changing representations and on the emergence of cohesive cross-border regions. The aims of the project do not necessitate strong stakeholder involvement; however, in one of the case studies, indirect influence on actors has been observable in the course of in-depth interviews and opinion-surveys at least to the extent of raising awareness. (The sub-research titled "Mediascapes" focuses on relations between mediated representations - television programmes and newspapers - and contrasts those with institutional practices of cross-border interaction in the FinnishRussian and Finnish-Estonian contexts.) Besides, the findings from the different enquires into the "softer" bordering processes serve as important sources of insight for policyrelevant researches such as Terco, Ulysses or Euborderregions, which themselves do not carry out such primary data collection. Finally, border studies from different perspectives can also draw upon the elaborate conceptual model around "unfamiliarity".

\section{Conclusions}

Case studies offer opportunities to delve deep in (regional) specificities, investigate into embedded story-lines, and therefore provide a detail-rich insight into the situation at particular borders. Also, case studies can be a good summary of up-to-date information on border-related processes for regional actors. Yet, it is a general claim that without appropriate comparative analysis and abstraction of case study findings, without the use of typologies and the construction of general models, these studies would stay inwardslooking and bearing little meaning for general border theories or higher-level (e.g. European) policy making. The research projects drawn on as examples in this paper found different means to avoid this risk within their specific timeframes and financial resource limits; three of them, for instance, apply more or less standardized methods to examine different border regions in Europe. The task of the projects is not easy bearing in mind, among other things, the unchangeable geographical realities (the "European diversity") that prevent implementing the exact same toolkit in empirical fieldwork, or having to study a group of border regions that is not chosen by the researchers following a "replication logic" (see Yin, 2009), but that is predefined depending on the parties that take part in the realization of project or finance it.

Researchers participating in these projects not only use but also can potentially develop conceptual-analytical models and thus are able to contribute to border theory. For this, however, they have to find appropriate ways to draw general inferences from their casespecific, contextual data. Within the research process there are different stages where cross-case (or cross-regional) comparisons can be carried out to be able to overcome the problem of "introverted" case studies. The most obvious stages are the beginning and the end: that of "raw" data and of findings. The former, attempted also in Ulysses and TERCO, requires standardised and truly comparable data, which was a concrete limitation in both projects. Besides, even if standard data had been available, special place-based, contextual variables which bear crucial relevance to the measured phenomena could stay undetected with this method. At the other end of the scale, case study reports can be synthesized "ex-post" into executive summaries, which themselves, too, are often longer, descriptive-analytical texts. Both to produce and interpret these are labour intensive 
tasks, and there is a risk that these summaries still stay fragmented along the different specific regional contexts. Nevertheless, a standard thematic structure or shared "table of contents" for drafting case study reports can help to produce better synopses that go beyond the summation of cases (used for instance, in Euborderregions). Neither of these two solutions can be entirely trusted, nor disposed of, but extra caution is required regarding what our data represents, and what conclusions are safe to draw and what not.

The most challenging option is when the comparison across case studies is (also) facilitated on a "medium level". This requires a conscious and systematic insertion of analytical tools across the whole research design (and in all case study investigations) that emerge from the theoretical starting position and the research questions. We can trace this approach in our example projects, too. For instance, Terco's factors, domains and governance types of territorial co-operation used in the project starting from framing the questions and collecting data, through typology creation till structuring the descriptive case studies and reconfirming the conceptual models. Also, the broad model of "Unfamiliarity" was initially set up to harmonise the sub-researches and then was enriched by the multidisciplinary inputs.

As to the requirement to be policy-relevant on various levels, it is obvious that where funding and research themes originate from the European Commission, the research objectives and designs are obliged to translate scientific results into policy language; which is the case with three of our projects. This has clear implications also to implementing a more systematic comparative framework. For European-level decision makers, research can provide structured evidence of the diversity across the different border situations, which is produced by way of relating, comparing the particular cases with each other and by classifying them according to different aspects. Case studies are also crucial in raising the EU's awareness of the existence of "regional specificities". On the other hand, from the perspective of the regions themselves, outcomes from comparative analyses offer an opportunity to position themselves relative to other similar cases and learn from European analogies (see for instance, in Ulysses, and to some extent, Euborderregions). Not only the applicability of research findings, but also their verification and their targeted communication can be ensured by stakeholder engagement in the research process. From the example projects studied in the paper, it is visible that there is a wide range, or "continuum" of stakeholder engagement possible to realise for these different purposes and at different stages of the research. Truly, having stakeholders involved more than as interviewees or recipients of research reports is time and resource consuming, yet, it could prove to be the right investment for good added value.

Within the limits of this paper, it was not possible to introduce all the methodological intricacies of the four projects, but to focus on two main aspects that impact their research designs: a comparative framework serving generalisation and policy-relevance of research findings. These issues turn out to be inter-related: a comparative framework is useful not only for conceptual modelling and where necessary, for distilling out general (European-level) policy messages. It also helps local/regional stakeholders to position themselves in their wider (European) context and relate more to macro-level processes and European policy. Despite the fact that a strong involvement in the research of regional actors increases the pressure on researchers to delve more into specificities, the engagement of stakeholders from various decision-making levels in the research process offers a favourable interface between "theory" and "practice". 
Finally, with respect to fulfilling the fundamental need to contribute to the conceptual development and coherence of border studies, we need to refer back to the point made above about carrying out abstractions, generalisations on a "middle level" or interimstage in the research design and process. Comparative case study researches on borders in Europe have burgeoned due to heightened policy interest (and funding), so there is already a great volume of information about specific border regions and settings. If these researches can operate along existing theoretical lines, and can advance those with generalisations on appropriate levels, their specific field can produce clearer messages to communicate towards the broader, interdisciplinary border study scholarship.

\section{BIBLIOGRAPHY}

BÖHME K. \& GLØERSEN E. (2011), “Territorial Cohesion Storylines: Understanding a Policy Concept”, Spatial Foresight Brief 2011-1, Luxembourg, Spatial Foresight, www.spatialforesight.eu/ tl_files/files/editors/dokumente/Brief-2011-1-111025.pdf, accessed 12/02/2013.

DAVOUDI S. (2006), "Evidence-Based Planning: Rhetoric and Reality", disP - The Planning Review, 165, Zurich, Network City and Landscape, pp. 14-24.

DENZIN N.K. (1983), “Interpretive interactionism”, in GARETH M. (Ed.), Beyond method: Strategies for social research, Beverly Hills, Sage, pp. 129-146.

ESKELINEN H. \& FRITSCH M. (2010), "Repositioning the EU”s Northernmost Regions in a European Territorial Context", Space is Luxury. Selected Proceedings of the $24^{\text {th }}$ AESOP Annual Conference, Centre for Urban and Regional Studies Publications B103, Espoo, Aalto University, pp. 188-203.

EUBORDERREGIONS project (2011-2015), European Regions, EU External Borders and the Immediate Neighbours - Analysing Regional Development Options through Policies and Practices of Cross-Border Cooperation, funded within the European Union"s Seventh Framework Programme, www.euborderregions.eu.

FISHKIN J.S. \& LASLETT P. (eds.) (2003), Debating Deliberative Democracy, Malden, Blackwell. KOLOSSOV V. (2005), "Border Studies: Changing Perspectives and Theoretical Approaches", Geopolitics, 10, 4, London, Routledge, pp. 606-632.

MAYRING P. (2007), “On Generalization in Qualitatively Oriented Research”, Forum Qualitative Sozialforschung/Forum: Qualitative Social Research, 8, 3, Art. 26, http://nbn-resolving.de/ urn:nbn:de:0114-fqs0703262, last accessed 11/06/2013.

NEWMAN D. (2006), "Borders and Bordering. Towards an Interdisciplinary Dialogue", European Journal of Social Theory, 9, 2, London, Sage, pp. 171-186.

PAASI A. (2009), “A Border Theory: An Unattainable Dream or a Realistic Aim for Border Scholars?", The Ashgate Research Companion to Border Studies, Farnham, Surrey, Ashgate, pp. 11-31. SCOTT J.W. (ed.) (2006), EU Enlargement, Region-Building and Shifting Borders of Inclusion and Exclusion , Border Regions Series, Aldershot, Ashgate. 
TERCO project (2010-12), European Territorial Cooperation as a Factor of Growth, Jobs and Quality of Life , funded by the European Commission under the ESPON 2007 programme. Website and Final report: http://www.espon.eu/main/Menu_Projects/Menu_AppliedResearch/terco.html.

TERRITORIAL AGENDA OF THE EUROPEAN UNION 2020. Towards an Inclusive, Smart and Sustainable Europe of Diverse Regions. (2011), Gödöllő, Hungary.

TIMOTHY D.J. (1995), "Political Boundaries and Tourism. Borders as Tourist Attractions”, Tourism Management, 16, 7, Guildford, Elsevier, pp. 525-532.

VALENTINE G. (2008), “Living with Difference: Reflections on Geographies of Encounter”, Progress in Human Geography, 32, 3, London, Sage, pp. 323-337.

VAN HOUTUM H. (1999), "Internationalisation and Mental Borders", Journal for Economic and Social Geography, 90, 3, Oxford, Royal Dutch Geographical Society KNAG, Blackwell, pp. 329-335.

VAN HOUTUM H. \& LAGENDIJK A. (2001), “Contextualising Regional Identity and Imagination in the Construction of Polycentric Urban Regions: the Cases of the Ruhr Area and the Basque Country", Urban Studies, 38, 4, London, Sage, pp. 747-767.

VAN HOUTUM H. \& van NAERSSEN T. (2002), "Bordering, Ordering and Othering”, Tiijdschrift voor Economische en Sociale Geografie, 93, 2, Oxford, Royal Dutch Geographical Society KNAG, Blackwell, pp. 125-136.

ZAPLETAL J. (2010), “The European Grouping of Territorial Cooperation (EGTC): a New Tool for Facilitating Cross-border Cooperation and Governance", Quaestiones Geographicae, 29, 4, Poznan, Bogucki Wydawnictwo Naukowe, pp. 15-26.

ULYSSES project (2010-2012), Using Applied Research Results from ESPON as a Yardstick for Crossborder Spatial Development Planning, funded by the European Commission under the ESPON 2013 Programme, http://www.espon.eu/main/Menu_Projects/Menu_TargetedAnalyses/ulysses.html.

UNFAMILIARITY project (2010-2013), Unfamiliarity as signs of European times: scrutinizing historical representations of otherness and contemporary daily practices in border regions, funded by: Academy of Finland, Finland; The Danish Council for Independent Research - Humanities, Denmark; Research Foundation Flanders, Belgium; Netherlands Organisation for Scientific Research, The Netherlands; the European Science Foundation, http://www.unfamiliarity.eu/

\section{NOTES}

1. "Targeted analyses" are a new type of ESPON projects that were developed to meet the needs of local actors, policy makers and organisations dealing with regional development to view their territories in a wider (European) context, and to make comparisons to other regions and cities.

\section{ABSTRACTS}

This paper is concerned with the research design of four recent border related research projects, all operating in European multi-case study frameworks. All these studied projects have the aim of 
producing, on the one hand, regionally specific research results and, on the other hand, results that bear relevance to general border theories. Furthermore, most of these researches have to provide messages for policy makers and not only on the local-regional but on a more general, European level. This paper discusses what research designs the projects have chosen to operate in to reach all of these objectives. The focus is on two major aspects that have an impact on the research designs and are connected to the need for abstraction from specific contextual cases: comparative framework and policy relevance on different levels.

Cet article examine comment quatre projets récents consacrés à l'étude des frontières, tous opérant dans des cadres européens d'études multi-cas, ont conçu leur travail de recherche. Ces études visent à produire à la fois des résultats spécifiques au niveau régional et des résultats pertinents pour les théories générales relatives aux frontières. En outre, la plupart de ces recherches sont censées ouvrir des pistes aux responsables politiques, tant au niveau localrégional qu'à l'échelle de l'Europe. L'article examine dans quels modèles de recherche les quatre projets ont choisi d'opérer pour répondre à ces différents objectifs. L'accent est mis sur deux aspects majeurs impactant les modèles de recherche et liés aux impératifs d'abstraction à partir de cas contextuels spécifiques: cadre comparatif et pertinence au niveau politique à différentes échelles.

\section{INDEX}

Mots-clés: approche par études multi-cas, élaboration d'une recherche comparative, étude des frontières européennes, pertinence en matière politique

Keywords: multiple-case study approach, comparative research design, European border research, policy relevance

\section{AUTHORS}

\section{SAROLTA NÉMETH}

$\mathrm{PhD}$ (SocSc), project researcher at the Karelian Institute, UEF (University of Eastern Finland, Joensuu, Finland), Sarolta.Nemeth@uef.fi

\section{ÁGNES NÉMETH}

M.Sc., M.A., doctoral candidate at the Karelian Institute, UEF (University of Eastern Finland, Joensuu, Finland), Agnes.Nemeth@uef.fi

\section{VIRPI KAISTO}

M.A., project researcher at the South Karelian Institute (Lappeenranta University of Technology, Finland) Virpi.Kaisto@lut.fi 